\title{
The future of general practice in China:
}

\author{
from 'barefoot doctors' to GPs?
}

\section{'BAREFOOT DOCTORS'}

The concept of the 'barefoot doctor' was developed as part of China's infamous Cultural Revolution: an estimated 1 million agricultural workers were trained to meet rural health needs for sanitation, health education, first aid, and primary care. ${ }^{1}$ They received little formal instruction and received mainly 'on the job' training. Similar programmes were established to create 'worker doctors' in factories and 'Red Guard doctors' who were housewives serving as physicians' assistants in urban health stations. The 'barefoot doctors' made significant contributions to infectious disease control as well as the expansion of primary care in rural China with infant mortality rates falling dramatically between 1950 and 1982. ${ }^{2}$

In 2009 China announced a comprehensive 3-year Health Care Reform programme with the primary aim of ensuring universal access to health care for the whole population of 1.3 billion. $^{3}$ There are a number of components to this programme, which include better primary care (especially in rural areas) and universal access to health insurance. The central government has invested part of the allocated 850 billion Yuan lapproximately £85 billion) to fund the development of rural health care so that every village will have a clinic and thousands of community level clinics will be either built or upgraded in urban areas. This programme has been followed by a capacity-building plan to address the serious shortage of GPs available to deliver community based care: China intends to train an additional 300000 GPs by $2020{ }^{4}$

\section{NON-COMMUNICABLE DISEASES}

'Barefoot doctors' were created to deal primarily with the challenge of infectious disease in rural areas; the new GPs, however, will need to address the growing problem of non-communicable diseases (NCDs) in both urban and rural areas and will require far more training than "barefoot doctors'. The future role envisaged for community services in China is not dissimilar to that of general practice in the UK with community-based responsibility for prevention, primary (first contact) care, and health education. ${ }^{5}$

However, the current healthcare system is not organised to address the treatment

\section{"Chinese people tend to seek high-level care even for minor self-limiting conditions.}

and management of the main causes of chronic disease in China - cardiovascular disease, chronic obstructive pulmonary disease, diabetes mellitus, and lung cancer - despite the expectation that the frequency of these four conditions will double or even triple' over the next two decades in people $>40$ years of age if effective preventative measures are not taken. ${ }^{6}$ For example, the current rate of smoking among Chinese men is approximately $54 \%$ and the average intake of salt is $>12 \mathrm{~g}$ per day ltwice the current World Health Organization recommendation).

Around $90 \%$ of the Chinese population now have some form of medical insurance, mostly as part of the government supported New Cooperative Medical System that operates at a local (county) level. Premiums vary widely across the country depending on local mean income but they are generally fixed at an affordable level.

Another problem is that Chinese people tend to seek high-level care even for minor, self-limiting conditions. ${ }^{8}$ Since they do not currently need to get a referral from primary care, patients present at secondary and tertiary facilities with often unrealistic expectations and when treatment fails doctors are deemed responsible, leading increasingly to violent confrontation. ${ }^{7}$

\section{GENERAL PRACTICE IN CHINA}

The typical GP set-up in China is a community health centre with six or seven sub-clinics employing $50 \mathrm{GPs}$ and 50 nurses. However, the precise role of the GP within the new system of health care remains to be defined and despite this enormous investment, serious problems remain in access to treatment, quality of care, and costs of health care to people in poorer areas. ${ }^{9}$ Patients prefer to attend hospitals since primary care doctors are less qualified than their hospital colleagues. For example, in 2008, the number of outpatient visits per hospital bed was 1048 in China compared to 313 in England. ${ }^{10}$

A huge amount of progress has been made developing general practice in China and a number of successful diverse models of 'general practice' have been used to pilot current policy in different parts of the country. It is clear from the experience of 50 pilot sites that multidisciplinary teams delivering health care in the community are an essential component of all the models that have been developed. However, the attractiveness of general practice to doctors needs to be improved. At the moment the incentives to become a GP are poor and it is essential that new GPs can be offered:

- a guaranteed income lprovided by the government or the market linked to the pricing of medical services); and

- improved career prospects and status with opportunities for promotion. continuing professional development, and for academic research and teaching.

\section{GENERAL PRACTICE DEVELOPMENT}

Policy guarantees need to be in place because they are not yet fixed and young doctors will be reluctant to commit themselves to a career if there is no guarantee that the policy of developing general practice will continue following the end of the current reforms.

There is also currently a huge lack of qualified trainers and it is essential to develop community-based clinical training 
“It will probably take at least one generation for people ... to appreciate the importance of community care.

centres ('teaching practices') as well as university academic departments so that medical students can see general practice as an attractive high status career. In addition, the research that such departments should undertake should be initially focused on the development of Chinese Quality Indicators for General Practice and their implementation (namely, the QOF).

Finally, an 'attractive offer' has to be made to potential patients for them to register with an individual GP team and linked to this is the importance of high-quality medical records that could be kept by the patient and brought to each consultation (such as child health records in the UK). Linked to this is the importance of developing a single standard for IT systems.

It will probably take at least one generation for people in the community to appreciate the importance of community care, develop trust in a registered GP (in terms of treatment and referral), and to value the role of the 'expert generalist'.

In summary, a fundamental challenge for the China Health Care Reform is to increase the use of primary care, which is affordable and appropriate for most conditions. Early reports suggest a small shift in flows away from secondary and tertiary facilities, ${ }^{11}$ but the solution may have to be more radical, with general practice being given a gatekeeping role:

'Who cares if a cat is black or white, as long as it catches mice!' (Deng Xiaoping, 1961).

\section{Nigel Mathers,}

Professor of Primary Medical Care, Academic Unit of Primary Medical Care, University of Sheffield, Sheffield.

\section{Yu-Chu Huang,}

Associate Professor, Department of Nursing, Fu-Jen Catholic University, New Taipei City, Tiawan. Republic of China.

\section{Provenance}

Commissioned; not externally peer reviewed.

DOI: 10.3399/bjgp14X679933

\section{ADDRESS FOR CORRESPONDENCE}

\section{Nigel Mathers}

Academic Unit of Primary Medical Care, University of Sheffield, Samuel Fox House, Northern General Hospital, Herries Road, Sheffield, S5 7AU, UK.

\section{E-mail: n.mathersđsheffield.ac.uk}

\section{REFERENCES}

1. Sidel WW. The barefoot doctors of the People's Republic of China. N Engl J Med 1972; 286: 1292-1300.

2. Brown RE, Piriz DG, Liu Y, Moore J. Reforming health care in china. historical, economic and comparative perspectives. PUBPOL 716. 2012.

3. Yip WCM, Hsiao WC, Chen W, et al. Early appraisal of China's huge and complex health care reforms. Lancet 2012; 379: 833-842.

4. Anonymous. China's major health challenge: control of chronic diseases. Lancet 2011; 378: 457

5. Liu LQ, Li J, Li H, et al. A survey on the present situation of Chinese community health service - the present situation of 'Six $n$ One' in community health service stations of the Eastern, Middle and Western Areas. (In Chinese). Chinese General Practice 2005; 21(8): 1744-1745.

6. World Bank Report. Toward a healthy and harmonious life in China: stemming the rising tide of non-communicable diseases (English). World Bank Report Number 62318-CN, 2011 http://www-wds.worldbank.org/external/ default/WDSContentServer/WDSP/IB/2011/0 7/25/000333037_20110725011735/Rendered/ PDF/634260WP00Box30officialOuse0only090. pdf (accessed 6 May 2014).

7. Hesketh T, Wu D, Mao L, Ma N. Violence against doctors in China. BMJ 2012; 345: e5730.

8. Huang $Y$, The sick man of Asia: China's Health Crisis. Foreign Affairs 2011; 6: 119-136.

9. Organisation of Cooperation and economic Development. Economic Survey of China 2010. http://wnw.oecd.org/economy/surveys/ economicsurveyofchina2010executive summary.htm (accessed 6 May 2014).

10. Zaracostas J. Chronic diseases among the over $40 \mathrm{~s}$ in China are set to double over the next 20 years. BMJ 2011; 343: d4801.

11. Meng $Q, X u L$, Zhang $Y$, et al. Trends in access to health services and financial protection in China between 2003 and 2011: a crosssectional study. Lancet 2012; 379: 805-814. 